\title{
MEMBANGUN RELASI DI ATAS ZAWIYAH
}

\author{
Otong Surasman \\ Institut PTIQ Jakarta \\ otongmomonsurasman@gmail.com
}

\begin{abstract}
Abstrak
Di zaman modern ini, meskipun kemajuan teknologi semakin maju dan alat komunikasi semakin canggih, akan tetapi ada sesuatu yang hilang yang terlupakan oleh kebanyakan manusia. Bahkan, yang lebih menyedihkan adalah mulai hilangnya kekhusyu' an dalam melaksanakan ibadah shalat, yang dilakukan oleh umat Islam saat ini. Sebagai barometernya begitu sangat sederhana, petama sebagian besar umat Islam saat ini buta huruf Al-Qur'an mencapai $65 \%$ lebih dan kedua umat Islam masih di bawah kebodohan dan kemiskinan, yang menunjukkan bahwa umat Islam tidak bersatu padu dalam menyelesaikan masalah umat. Masing-masing mementingkan kepentingan pribadi dan golongannya, dibandingkan untuk menyelesaikan kepentingan bersama. Salah satu upaya yang sangat penting untuk membangun umat, agar bisa mencapai kekhusyu'an dalam melaksanakan ibadah shalat, mampu membangun ekonomi umat dalam memberantas kemiskinan dan kebodohan, maka memulai kembali membangun relasi dengan Allah SWT di atas Zawiyah. Hal ini merupakan sebagai alat kontrol yang sekaligus memohon petunjuk kepada Allah SWT, agar setiap masalah yang dihadapi pribadi umat Islam maupun masyarakat diberikan solusi jalan keluarnya.
\end{abstract}

Kata kunci: Bangunan, Hubungan, Zawiyah

\begin{abstract}
In this modern era, even though advances in technology are increasingly advanced and communication tools are increasingly sophisticated, there is something missing that is forgotten by most humans. In fact, what is even more sad is the loss of specialties in performing prayer services, which are carried out by Muslims today. As the barometer is so very simple, the majority of Muslims today Al-Qur'an illiteracy reaches 65\% more and both Muslims are still under ignorance and poverty, which shows that Muslims are not united in solving the problems of the people. Each of them prioritizes their personal and group interests, compared to resolving common interests. One very important effort to build a people, in order to achieve success in performing prayer services, is able to build the people's economy in eradicating poverty and ignorance, then start building relationships with Allah SWT above Zawiyah. This is a means of control which at the same time begs for guidance to Allah SWT, so that every problem faced by Muslims and the public is given a solution to the solution.
\end{abstract}

Keywords: Building, Relationships, Above Zawiyah 


\section{PENDAHULUAN}

Pelajaran yang sangat berharga dalam perjalanan hidup Rasulullah SAW adalah membangun relasi di atas Zawiyah. Mungkin istilah Zawiyah belum begitu populer dalam masyarakat, akan tetapi untuk mempermudah uraian jurnal ini, penulis gunakan kata Zawiyah, yaitu tempat khusus ukuran satu sajadah untuk mendekatkan diri kepada Allah SWT. Hal ini sebagaimana telah dilakukan oleh Nabi Muhammad SAW pertama kali di Gua Hira (Jabal Nur) kurang lebih 6 kilometer di sebelah utara Masjidil Haram Makkah Al-Mukarramah, di mana letak Gua Hira persis gambaran satu sajadah menghadap ke arab kiblat (Kabah).

Pada zaman sekarang ini, tentunya belum banyak umat Islam yang mempunyai Zawiyah di rumahnya masing-masing. Oleh sebab itu, melalui tulisan jurnal ini buatlah Zawiyah di rumah kita msing-masing, walaupun rumah kita tidak luas. Karena betapa pentingnya, peranan Zawiyah bagi seorang muslim yang menghendaki keakraban dengan Sang Maha Pencipta Allah SWT.

Lantas apa yang dilakukan di dalam Zawiyah? Sudah barang tentu beribadah kepada Allah SWT, dengan fokus tiga amalan utama yaitu: shalat, membaca Al-Qur'an dan dzikir, yang kesemuanya disertai dengan taddabur, tafakkur. Dalam bahasa sekarang, mengapa harus melakukan ibadah tersebut di Zawiyah? Karena perlu terciptanya satelit-satelit yang mampu mengakses alam langit ke bumi, dikala sang rasul sudah tiada. Sama halnya dengan para mahasiswa dan lainnya, ketika menggunakan Android selalu mengatakan sinyalnya kurang kuat, lemot dan lainnya.

Nah, fungsi Zawiyah di antaranya agar mampu mengakses informasi aktul dari langit untuk disampaikan ke bumi, di mana saat ini penghuni bumi dalam kegelapan, sangat perlu adanya cahaya yang mampu menyinari jalan hidupnya.

Buktinya apa bahwa saat ini dunia dalam kegelapan? Tidak mampunya mengaktualisasikan nilai-nilai kandungan Al-Qur'an dalam kehidupan nyata. Al-Qur'an hanya dijadikan dalil untuk menyampaikan tausiyah tanpa punya makna, karena yang menyampaikannya sendiri tidak mampu mengaktualisasikan isi kandungan Al-Qur'an. Bahkan yang terjadi adalah ibadah ritual jalan, akan tetapi maksiat tidak bisa ditinggalkan. Kerusakan akidah dan akhlak tumbuh berkembang diberbagai kalangan masyarakat, khususnya masyarakat Indonesia, yang dalam konsensus penduduk terbanyak di dunia.

Paling tidak, di dalam Zawiyah tersebut akan tumbuh berkembang kesadaran dalam menghadapi kehidupan ini, hidup di dunia hanya sementara, sebentar, sedangkan kehidupan di akhirat kekal selama-lamanya. Tanpa Zawiyah, kemungkinan sangat kecil akan munculnya kesadaran terhadap apa yang dilakukan oleh setiap manusia. Zawiyah selain tempat mengadukan semua persoalan kehidupan manusia kepada Allah SWT, juga berfungsi sebagai alat untuk introfeksi diri, merenungkan segala prilaku dan perbuatan manusia. Baik mengenai introfeksi harian, setelah bekerja seharian penuh, maka pada saat berada di rumah masing-masing, luangkanlah waktu sebelum beristirahan untuk mengambil air wudhu dan lakukan shalat sunnah dua raakaat, kemudian lakukan introfeksi diri, apa yang telah dilakukan seharian penuh? Kalau ada hal-hal yang membuat dosa, maka mintalah ampunan kepada Allah SWT. Kalau ternyata banyak melakukan perbuatan baik, maka bersyukurlah kepada Allah SWT, karena mampu mengisi kehidupan dengan penuh makna, bermanfaat dan bernilai ibadah.

Introfeksi diri yang harus dilakukan oleh setiap manusia, Allah SWT memberikan informasi secara tegas dalam firman-Nya sebagai landasan untuk dijadikan pijakan setiap manusia, agar mampu melakukannya setiap saat, khususnya yang paling tepat adalah ketika merebahkan diri untuk beristirahat, setelah seharian melakukan aktivitas. Yaitu firman Allah SWT dalam surah Al-Hasyr/59 ayat 18 - 20,

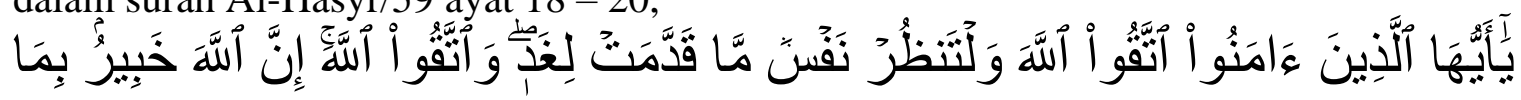




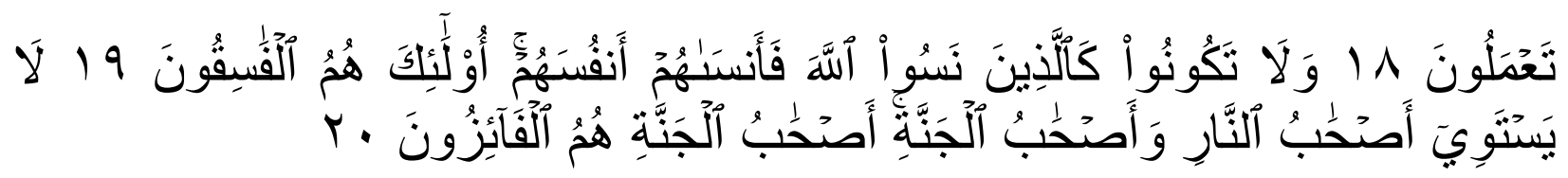

Hai orang-orang yang beriman, bertakwalah kepada Allah dan hendaklah setiap diri memperhatikan apa yang telah diperbuatnya untuk hari esok (akhirat); dan bertakwalah kepada Allah, sesungguhnya Allah Maha Mengetahui apa yang kamu kerjakan. Dan janganlah kamu seperti orang-orang yang lupa kepada Allah, lalu Allah menjadikan mereka lupa kepada mereka sendiri. Mereka itulah orang-orang yang fasik. Tidaklah sama penghuni-penghuni neraka dengan penghuni-penghuni jannah; penghuni-penghuni jannah itulah orang-orang yang beruntung. (Q. S. Al-Hasyr/59: 18 - 20).

Kemudian ada beberapa informasi penting dalam kitab suci Al-Qur'an, khususnya dalam membangun relasi di atas Zawiyah, yaitu:

Pertama, informasi mengenai kedekatan Allah SWT dengan hamba-Nya, sebagaimana dijelaskan dalam firman Allah SWT surah Al-Baqarah/2 ayat 186,

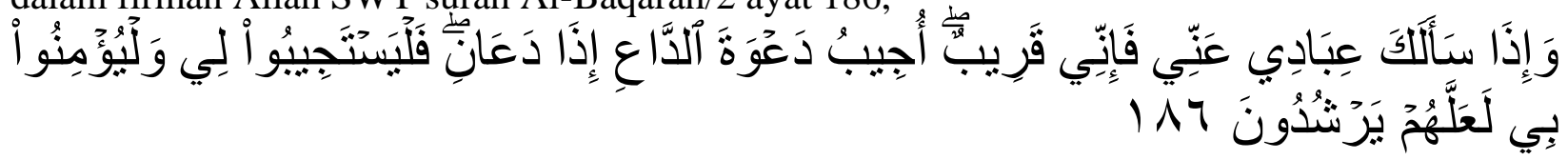

Dan apabila hamba-hamba-Ku bertanya kepadamu tentang Aku, maka (jawablah), bahwasanya Aku adalah dekat. Aku mengabulkan permohonan orang yang berdoa apabila ia memohon kepada-Ku, maka hendaklah mereka itu memenuhi (segala perintah-Ku) dan hendaklah mereka beriman kepada-Ku, agar mereka selalu berada dalam kebenaran.

Kedua, infromasi dengan mengingat Allah SWT (berdzikir) hati manusia menjadi tenang, damai, dan tentram, sebagaimana uraikan dalam firman Allah SWT pada surah Ar-Ra'd/13 ayat 28,

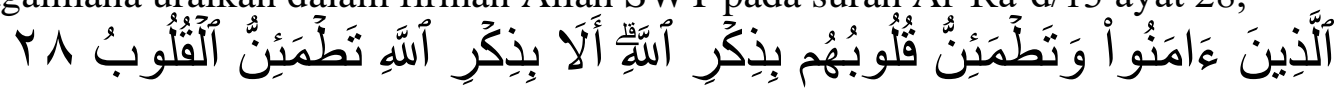

(yaitu) orang-orang yang beriman dan hati mereka manjadi tenteram dengan mengingat Allah. Ingatlah, hanya dengan mengingati Allah-lah hati menjadi tenteram.

Ketiga, informasi agar berupaya merenungkan ciptaan Allah SWT, termasuk penciptaan langit dan bumi, serta silih bergantinya malam dan siang, sebagaimana dijelaskan dalam firman Allah SWT surah Ali 'Imran/3 ayat $190-191$,

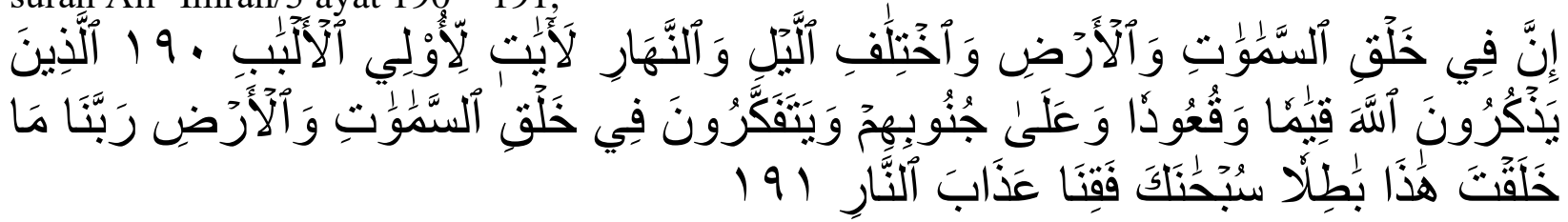

Sesungguhnya dalam penciptaan langit dan bumi, dan silih bergantinya malam dan siang terdapat tanda-tanda bagi orang-orang yang berakal, (yaitu) orang-orang yang mengingat Allah sambil berdiri atau duduk atau dalam keadan berbaring dan mereka memikirkan tentang penciptaan langit dan bumi (seraya berkata): "Ya Tuhan kami, tiadalah Engkau menciptakan ini dengan sia-sia, Maha Suci Engkau, maka peliharalah kami dari siksa neraka.

Keempat, informasi perintah Allah SWT kepada Rasulullah SAW agar bersabar bersama orang-orang yang selalu mendekatkan diri kepada Allah SWT, sebagaimana diterangkan dalam firman-Nya surah Al-Kahfi/18 ayat 28,

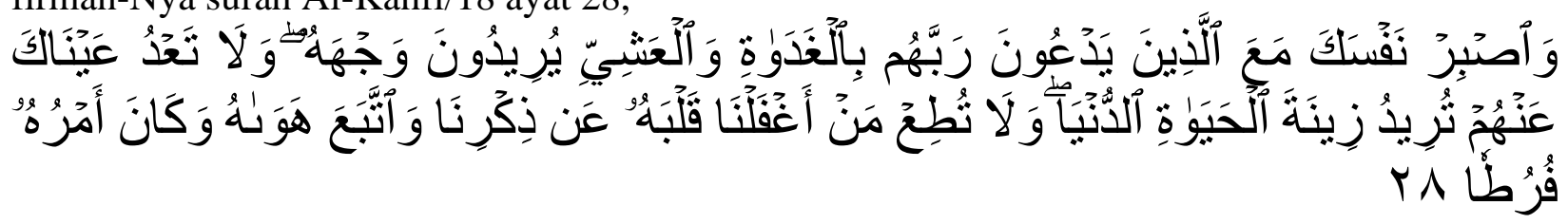


Dan bersabarlah kamu bersama-sama dengan orang-orang yang menyeru Tuhannya di pagi dan senja hari dengan mengharap keridhaan-Nya; dan janganlah kedua matamu berpaling dari mereka (karena) mengharapkan perhiasan dunia ini; dan janganlah kamu mengikuti orang yang hatinya telah Kami lalaikan dari mengingati Kami, serta menuruti hawa nafsunya dan adalah keadaannya itu melewati batas.

Kemudian timbul sebuah pertanyaan apa yang harus di bangun di atas Zawiyah? Maka jawabannya adalah:

Pertama, mempertahankan untuk melakukan shalat tahajud secara istiqamah, sebagaimana dijelaskan dalam firman Allah SWT pada surah Al-Isra'/17 ayat 79,

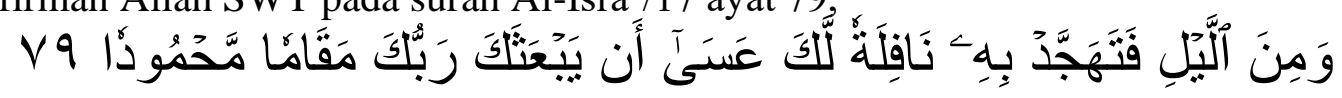

Dan pada sebahagian malam hari bersembahyang tahajudlah kamu sebagai suatu ibadah tambahan bagimu; mudah-mudahan Tuhan-mu mengangkat kamu ke tempat yang terpuji.

Kedua, memperbanyak dzikir pada waktu pagi dan sore, sebagaimana diterangkan dalam firman Allah SWT surah Al-Ahzab/33 ayat $41-42$,

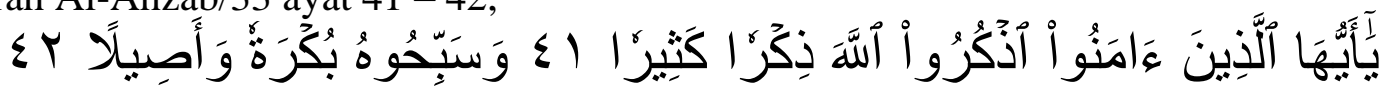

Hai orang-orang yang beriman, berzdikirlah (dengan menyebut nama) Allah, zikir yang sebanyak-banyaknya, dan bertasbihlah kepada-Nya diwaktu pagi dan petang.

Ketiga, memperbanyak membaca Al-Qur'an, yang sudah jelas banyak sekali manfaat yang diraih bagi para pembacanya. Paling tidak dengan membaca Al-Qur'an akan terbebas dari aduan Rasulullah SAW, pada hari Kiamat nanti sebagaimana dijelaskan pada firman-Nya surah Al-Furqan/25 ayat 30,

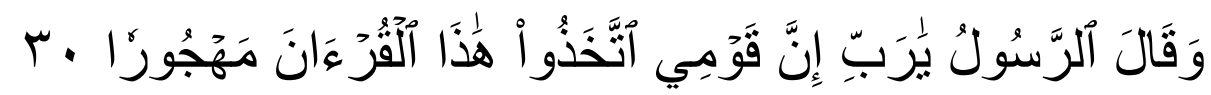

Berkatalah Rasul: "Ya Tuhanku, sesungguhnya kaumku menjadikan Al Quran itu sesuatu yang tidak diacuhkan".

M Quraish Shihab dalam tafsir Al-Mishbah, menukil pendapat Ibn Al-Qayyim sebagai berikut: "Banyak hal yang dicakup oleh kata mahjuran pada ayat di atas, antara lain:

a. Tidak tekun mendengarkan Al-Qur'an.

b. Tidak mengindahkan halal dan haram - walau dipercaya dan dibaca.

c. Tidak menjadikannya rujukan dalam menetapkan hukum menyangkut Ushul ad-Diin (prinsip-prinsip ajaran agama dan rinciannya.

d. Tidak berupaya memikirkan apa yang dikehendaki oleh Allah SWT yang menurunkannya.

e. Tidak menjadikannya obat bagi semua penyakit-penyakit kejiwaan.

Dari beberapa informasi penting yang diuraikan firman Allah SWT di atas, perihal mengapa manusia harus membangun relasi di atas Zawiyah, memberikan petunjuk kepada manusia, agar terus berupaya mendekatkan diri kepada Allah SWT. Kemudian Allah SWT memberikan informasi pula, apa yang harus dibangun, yaitu: melaksanakan shalat tahajud secara istiqamah, berdzikir kepada pagi dan sore, juga dengan memperbanyak membaca Al-Qur'an secara baik dan benar.

Nah, inilah dasar-dasar yang harus dibangun di atas Zawiyah, setiap individu yang mengaku seorang Muslim, sehingga dapat dibayangkan dari sekian ratusan jumlah umat Islam di seluruh dunia dan khususnya di Indonesia, yang mempunyai Zawiyah begitu hanya sedikit sekali. Hal ini disebabkan karena kurangnya memahami konsep dasar kehidupan, yang harus dibangunnya. Padahal banyak dikalangan manusia, yang mahir di dalam berorganisasi, mengatur berbagai persoalan kehdiupan duniawi, akan tetapi secara pribadi begitu sangat lemah dihadapan Allah SWT. Bahkan yang lebih mengerikan, banyak manusia yang melupakan Allah SWT dalam 
menempuh kehidupan sehari-harinya, walaupun tampak taat ibadah pada lahiriyahnya, tetapi tidak mempunyai nilai, hampa dan gersang, hal ini terbukti tidak mampunya mengaplikasikan nilai-nilai firman Allah SWT dalam kehidupan.

Sebagai sebuah analisa - bagaimana mungkin dapat membangun sebuah bangsa yang dapat mewujudkan kesejahteraan yang berkadilan, sementara secara personal tidak mampu membangun relasi dengan Sang Maha Pencipta dengan baik? Kemampuan akal manusia terbatas, perlu adanya petunjuk, bimbingan yang lurus, yaitu kitab suci Al-Qur'an. Dalam kitab suci Al-Qur'an secara rinci setiap persoalan yang dihadapi manusia, pada dasarnya sudah tertuang dengan jelas, tinggal mencocokan setiap probadi manusia meleburkan diri ke dalam kitab suci Al-Qur'an.

Oleh sebab itu, betapa pentingnya membangun relasi di atas Zawiyah ini, sebagai sebuah upaya membangun relasi hubungan vertikal dengan Allah SWT, yang kemudian ketika membangun relasi hubungan horisontal dengan sesama manusia, bahkan dengan alam semesta sekitar lingkungan manusia, sudah mempunyai konsep dan pola-pola kehidupan yang terarah menuju jalan yang lurus dan benar. Di mana pada saat Rasulullah SAW membangun relasi di atas Zawiyah (Gua Hira/Jabal Nur), menggunakan syariat Nabi Ibrahim AS, maka saat ini kita membangun relasi di atas Zahwiyah berdasarkan kitab suci Al-Qur'an.

Al-Qur'an Al-Karim sudah lengkap Allah SWT turunkan kepada Nabi Muhammad SAW, melalui perantaraan malaikat Jibril AS, dan saat ini Al-Qur'an sampai kepada kita melalui jalur periwayatan yang mutawatir dari guru-guru kita. Untuk membuat pola-pola ini memang tidak mudah, akan tetapi ketika kita berupaya membangun relasi di atas Zawiyah, maka Allah SWT akan membimbing kita semua, sehingga mampu membuat pola-pola kehidupan dan beruapaya mewujudkannya dalam kehidupan nyata.

Pola-pola apakah yang dimaksud tersebut? Pola-pola tersebut adalah pencocokan pribadi kita terhadap ayat-ayat Al-Qur'an, khususnya menyangkut ayat-ayat yang berkaitan erat dengan kepribadian manusia dalam kehidupan sehari-hari. Tidak mungkin kita bisa mencocokkan dengan pola-pola tersebut, sementara kita tidak mengetahui pola-pola tersebut. Di sini terlihat sangat jelas, betapa pentingnya membangun relasi di atas Zawiyah, yaitu memohon bimbingan Allah SWT, agar dalam menempuh kehidupan sehari-hari selalu dekat dengan-Nya dan mendapatkan bimbingan menuju jalan yang lurus dan benar.

Beberapa pola-pola kehidupan yang harus dibangun oleh setiap manusia, khususnya umat Islam, yaitu:

Pertama, mencontoh 36 kepribadian atau karakater Nabi Ibrahim AS yang dibadikan Al-Qur'an, yang terurai dalam Al-Qur'an, di antaranya adalah: Waffâ surah an-Najm/53: 37, Shiddiq/benar surah Maryam/19: 41, Halîm, awwâh, munîb surah Hûd/11: 75, Muhsinîn surah ash-Shâffât/37: 100, Mu'minîn surah ash-Shâffât/37: 111, Ummah, qânitâ lillah, hanîfâ, lam yaku min al-Musyrikîn, Syâkirâ lian'umih surah an-Nahl/16: 120-123, Yakin, tenang hati surah al-Baqarah/2: 260, Tawakkal surah al-Mumtahanah/60: 4, Ikhlas, Muhsin, khalîlâ surah an-Nisâ'/4: 125, Berlepas diri, menepati janji, awwâh, halîm surah at-Taubah/9: 114 .

Kedua, mengetahui, memahami, mencocokkan dan mempraktekkannya dalam kehidupan sehari-hari sebagai orang yang bertakwa, yang terurai dalam Al-Qur'an, yaitu: surah Al-Baqarah/2 ayat $1-5$, surah Al-Baqarah/2 ayat 177 , surah Ali 'Imran/3 ayat $15-17$, surah Ali 'Imran/3 ayat $102-105$, surah Ali 'Imran/3 ayat $133-136$.

Ketiga, mengetahui, memahami, mencocokkan dan mempraktekkannya dalam kehidupan sehari-hari sebagai orang yang beriman, yang terurai dalam Al-Qur'an, yaitu: surah Al-Anfal/8 ayat $2-4$, surah At-Taubah/9 ayat $20-22$, surah At-Taubah/9 ayat $71-72$, surah At-Taubah/9 
ayat $111-112$, surah Al-Mu'minun/23 ayat $1-11$.

Keempat, mengetahui, memahami, mencocokkan dan mempraktekkannya dalam kehidupan sehari-hari sebagai orang yang berakal sehat, yang terurai dalam Al-Qur'an, yaitu: surah Al-Baqarah/2 ayat 164, surah Ali 'Imran/3 ayat 190 - 191, surah Ar-Ra'd/13 ayat 19-24.

Kelima, mengetahui, memahami dan mengamalkan kandungan Ya Nida dalam Al-Qur'an, yaitu panggilan khusus kepada orang-orang yang beriman, yang isisnya adalah perintah dan larangan Allah SWT. Ya Nida' dalam Al-Qur'an - Yaa ayyuhaladziina aamanuu, terulang dalam Al-Qur'an 86 ayat, belum termasuk ayat turunannnya sebagai penjelasan dari Ya Nida' tersebut.

Minimal untuk langkah awal dapat menyesuaikan diri masing-masing yang terpola pada empat bagian pola di atas. Sebagai salah satu contoh adalah pencocokkan pribadi kita dengan lima karakter/kepribadian Nabi Ibrahim AS yang diabadikan Al-Qur'an pada surah An-Nahl/16 ayat 120 - 123, sebagai berikut:

Dalam Tafsîr al-Mishbah M Quraish Shihab memberikan penafsiran terhadap ayat di atas, sebagai berikut: "Sesungguhnya Nabi Ibrâhîm as adalah umat atau sosok manusia yang penuh keutamaan dan keteladanan lagi patuh sepenuh hati kepada Allah swt, dan hanif yaitu selalu cenderung kepada kebenaran lagi konsisten melaksanakannya. Dan sekali-kali bukanlah dia (Nabi Ibrâhîm as) sejak dahulu lagi secara terus menerus-bukanlah dia-termasuk orang-orang musyrik serta beliau tidak pernah menyekutukan Allah swt. Beliau adalah Nabi suci yang selalu mensyukuri nikmat-nikmat-Nya dengan ucapan dan perbuatannya. Karena kesyukurannya itulah, maka Allah swt telah memilihnya dengan pemilihan yang sempurna sebagai imam, nabi, dan rasul dan membimbingnya ke jalan yang lebar lagi lurus. Dan Kami anugerahkan kepadanya kebaikan yaitu kenyamanan hidup dan nama baik, sehingga selalu diagungkan dan dikenang di dunia. Dan sesungguhnya dia di akhirat nanti benar-benar termasuk kelompok orang-orang yang saleh, yaitu yang mantap kesalehannya sehingga memperoleh pula kebahagiaan ukhrawi.

Lebih lanjut beliau memberikan penjelasan berikut: "Kata ummah terambil dari kata атта-уаитти yang berarti menuju, menumpu, dan meneladani. Dari akar kata yang sama lahir antara lain kata umm yang berarti ibu dan imam yang maknanya pemimpin, karena keduannya menjadi teladan, tumpuan pandangan dan harapan. Nabi Ibrâhîm as, walau seorang diri namun menyatu dalam kebribadian beliau sekian banyak sifat terpuji yang tidak dapat terhimpun kecuali melalui ummah, yaitu sekelompok atau sekian banyak manusia. Karena itu, beliau dinamai oleh ayat ini ummah, dan dari sini beliau menjadi imam, yaitu pemimpin yang sangat perlu diteladani. Ada juga yang memahaminya dalam arti beliau sendiri telah menjadi umat tersendiri, karena ketika beliau diutus hanya beliau sendiri yang mengesakan Allah swt.

Muhammad bin 'Ăli bin Muhammad asy-Syaukanî, Fath al-Qadîr al-Jami' baina Fan ar-Riwayah wa ad-Dirayah min 'Ilm at-Tafsîr memberikan keterangan sebagai berikut: "Nabi Ibrâhîm as termasuk golongan yang beriman pada keesaan Allah swt. Beliau adalah teladan yang diikuti oleh para nabi dan Allah swt menjelaskannya pada sûrat ini, "Sesungguhnya Nabi Ibrâhîm as adalah ummah-seorang laki-laki yang mempunyai ilmu pengetahuan atau seorang laki-laki yang terkumpul pada dirinya semua kebajikan. Atau terkumpulnya karakteristik yang baik pada dirinya, atau ummah bermakna seorang imam/pemimpin. Serta seorang yang mempunyai pengetahuan, yang dengan pengetahuannya, maka diketahui pula mengenai peraturan-peraturan yang disyariatkan Allah swt. Qânitin orang yang taat kepada Allah swt, hanifa yang selalu cenderung kepada kebenaran, tidak pernah mempersekutukan Allah swt, juga termasuk orang yang selalu mensyukuri nikmat yang diberikan Allah swt kepadanya. Dan Allah swt memilihnya Nabi Ibrâhîm as dengan memberikan derajat kenabian secara khusus, memberikan petunjuk ke jalan yang lurus, yaitu ajaran Islam dan agama yang benar. Di dunia diberikan kebaikan dengan mempunyai karakteristik yang baik atau selalu berbuat kebajikan, sebagai bapaknya orang-orang yang saleh, 
selalu mendapat pujian yang baik, kenabian, diabadikan dalam shalat yang dilakukan umat Islam, juga menjadi ikutan semua pemeluk agama. Serta di akhirat termasuk golongan orang-orang yang saleh.

Lebih lanjut, Muhammad bin 'Ăli bin Muhammad asy-Syaukanî, Fath al-Qadîr al-Jami' baina Fan ar-Riwayah wa ad-Dirayah min 'Ilm at-Tafsîr memberikan pemaparan berikut: Kemudian Kami wahyukan kepada engkau wahai Nabi Muhammad saw, dengan ketinggian derajat engkau dan kemulyaan yang diturunkan kepadamu, dan engkau adalah pemimpinnya anak Ădam as, agar engkau mengikuti ajaran Nabi Ibrâhîm as. Dan dasar al-m,illah adalah nama syari'at Allah swt kepada hamba-Nya melalui lisan para nabi, serta yang dimaksud dengan ayat tersebut adalah perintah kepada Nabi Muhammad saw, agar mengikuti kepada ajaran Nabi Ibrâhîm as di dalam tauhid dan dakwah, pembebasan diri dari penyembahan berhala, memeluk agama dengan agama Islam, manasik haji, dan semua syari'at Nabi Ibrâhîm as, kecuali yang telah dihapus darinya.

Muhammad Abd al-Mun'im al Jamal, At-Tafsîr al-Farid Lil Qur'ân al-Majîd memberikan penafsiran berikut: Nabi Ibrâhîm as sebagai ummah, yaitu kelompok yang banyak dan Nabi Ibrâhîm as dinamakan dengan ummah karena terkumpulnya pada pribadi Nabi Ibrâhîm as keutamaan-keutamaan, walau pun beliau menyendiri maka sudah cukup menjadi ummah. Qânitan-tunduk dan taat; hanifa- kecenderungan untuk menjauhi diri dari kebatilan menuju kepada kebenaran sebagai muslim yang selalu mengesakan Allah swt, Allah swt memilihnya sebagai nabi dan memberikan petunjuk ke jalan yang lurus, yaitu agama Islam, dan memberikan kebaikan di dunia berupa kecintaan semua pemeluk agama kepada Nabi Ibrâhîm as. Juga disebutkan pula, bahwa kebaikan di dunia yang diberikan kepada Nabi Ibrâhîm as adalah ajaran agama dan syari'atnya. Dan Allah swt selalu memuji Nabi Ibrâhîm as sebagai al-Khalîl, rasul-Nya, imam yang mengesakan Allah swt, bapaknya para nabi, pembebas dari kemusyrikan dan dari penyimpangan golongan Yahudi dan Nasrani. Dan Allah swt, juga memuji Nabi Ibrâhîm as sebagai teladan semua, karena padanya terkumpul semua sifat yang baik, akhlak yang mulia, dan beliau bukan golongan Yahudi, Nasrani atau musyrik, tetapi beliau adalah sosok yang selalu mengesakan Allah swt dengan menjalankan segala perintah-Nya. Juga Nabi Ibrâhîm as adalah sosok yang selalu banyak mensyukuri nikmat yang Allah swt berikan kepadanya, sehingga Allah swt memilihnya sebagai nabi yang membawa ajaran agama Islam sebagai agama yang benar dan memberikan hidayah kepada jalan yang lurus, juga mengajak semua makhluk untuk mengikuti ajaran agama Islam. Dan di akhirat termasuk golongan orang-orang yang saleh, yang mendapatkan derajat yang tinggi dan surga yang penuh kenikmatan.

Dari beberapa uraian di atas, mengenai lima karakter/kepribadian Nabi Ibrahim AS, kita berupaya mencocokkan diri kita dengan karakter/kepribadian Nabi Ibrahim AS, yaitu:

Pertama, ummah sebagai pemimpin yang menjadi tauladan/contoh.

Kedua, taat, tunduk dan patuh kepada Allah SWT.

Ketiga, hanifa - kecenderungan untuk menjauhi diri dari kebatilan menuju kepada kebenaran sebagai muslim yang selalu mengesakan Allah swt.

Keempat, sejak dahulu lagi secara terus menerus-bukanlah dia-termasuk orang-orang musyrik serta beliau tidak pernah menyekutukan Allah swt.

Kelima, Nabi Ibrahim AS adalah Nabi suci yang selalu mensyukuri nikmat-nikmat-Nya dengan ucapan dan perbuatannya.

Siapa pun kita, apa pun profesi kita, bagaimana agar mampu mempraktekkan lima kepribadian Nabi Ibrahim AS di atas dalam kehidupan sehari-hari, sebagaimana Allah SWT perintahkan kepada Nabi Muhammad SAW, agar mengikuti millah Nabi Ibrahim As yang lurus (Q. S. An-Nahl/16: 123). 
Sebuah analisa dari lima kepribadian Nabi Ibrahim AS, pertama sebagai pemimpin yang menjadi tauladan - Nabi Ibrahim AS telah memberikan contoh tauladan, yang sampai saat ini tidak ada putusnya umat Islam melakukan thawaf mengelilingi Ka'bah setiap saat, apakah menyangkut thawaf wajib maupun thawaf sunnah. Tegaknya bangunan Ka'bah adalah jariyah Nabi IbrahimAS dan Nabi Isma'il AS sepanjang sejarah kemanusiaan akan terus mengalir pahalanya kepada kedua Nabi Mulia. Tatkala Nabi Ibrahim AS dan Nabi Isma'il AS selesai meninggikan bangunan Ka'bah, Nabi Ibrahim AS dan Nabi Isma'il AS tidak meminta upah atau bayaran kepada Allah SWT, yang diminta adalah ketika selesai meninggikan bangunan Ka'bah tersebut, agar diterima di sisi Allah SWT sebagai amal jariyah. Yang dalam bahasa sekarang adalah bagi siapa pun yang mendapat anugerah dari Allah SWT menempati sebuah jabatan, maka jadikanlah sebagai ladang amal jariyah, bukan untuk menambah beban masyarakat dan dosa pribadi.

Kedua, qanitallillah - taat, tunduk dan patuh kepada Allah SWT, dalam arti bagaimana agar manusia, khususnya umat Islam mampu membagi waktu 24 jam setiap harinya, dijadikan ibadah ladang ibadah kepada Allah SWT, mulai dari bangun tidur sampai pada waktu untuk tidur kembali, karena dasarnya setiap perbuatan baik yang dilakukan umat Islam adalah bernilai ibadah. Ketiga, hanifa - cenderung kepada kebenaran dan meninggalkan kebatilan, baik menyangkut dalam keimanan kepada Allah SWT, maupun dalam kaitannya dengan bermuamalah - kehidupan bermasyarakat, memegang prinsip hanifa. Bahkan dari kasab atau pekerjaan yang kita lakukan setiap hari, sebagaimana dijelaskan dalam firman Allah SWT surah Al-Baqarah ayat 168 dan 172, 173 ,

Hai sekalian manusia, makanlah yang halal lagi baik dari apa yang terdapat di bumi, dan janganlah kamu mengikuti langkah-langkah syaitan; karena sesungguhnya syaitan itu adalah musuh yang nyata bagimu. (Q. S. Al-Baqarah/2: 168).

Hai orang-orang yang beriman, makanlah di antara rezeki yang baik-baik yang Kami berikan kepadamu dan bersyukurlah kepada Allah, jika benar-benar kepada-Nya kamu menyembah. Sesungguhnya Allah hanya mengharamkan bagimu bangkai, darah, daging babi, dan binatang yang (ketika disembelih) disebut (nama) selain Allah. Tetapi barangsiapa dalam keadaan terpaksa (memakannya) sedang dia tidak menginginkannya dan tidak (pula) melampaui batas, maka tidak ada dosa baginya. Sesungguhnya Allah Maha Pengampun lagi Maha Penyayang. (Q. S. Al-Baqarah/2: 172 - 173).

Keempat, tidak pernah menyekutukan Allah SWT - memberikan pengajaran kepada kita, agar dalam beribadah tidak dicampuri dengan hal-hal yang berbau syirik, murni karena Allah SWT, baik ibadah mahdhah maupun ghair mahdhah.

Kelima, banyak bersyukur kepada Allah SWT, di mana dalam bentuk syukurnya Nabi Ibrahim AS tercatat dalam sejarah, setiap hari Nabi Ibrahim AS selalu menjamu kafilah yang melewati tenda besarnya di Hebron Palestina. Nabi Muhammad SAW bentuk syukurnya adalah disamping kedermawanan beliau, juga terwujud dalam bentuk shalat malamnya sampai kaki beliau bengkak karena lamanya berdiri dalam shalat. Lantas apa yang kita lakukan sebagai bentuk syukur kita? Maka, kita berupaya mencontoh kedua manusia utama dan mulia, Nabi Ibrahim AS dan Nabi Muhammad SAW dalam kehidupan sehari-hari kita, dengan membangun relasi di atas Zahwiyah menjadi manusia yang selalu memperbanyak membaca Al-Qur'an, memperbanyak melaksanakan shalat (shalat wajib dan shalat sunnah), memperbanyak dzikir kepada Allah SWT, dan berupaya ketika bermuamalah dalam kehidupan bermasyarakat termasuk orang-orang yang dermawan dalam bentuk relasi horizontal, sehingga terbentuk masyarakat yang penuh kesejahteraan dan keadilan. 
Landasan utama agar terbentuk masyarakat yang penuh kesejahteraan dan keadilan, sebagai bentuk dan wujud nyata membangun relasi horizontal, Allah SWT membimbing setiap manusia melalui firman-Nya surah Al-Baqarah/2 ayat 83 dan surah An-NIsa'/4 ayat 36, berirkut:

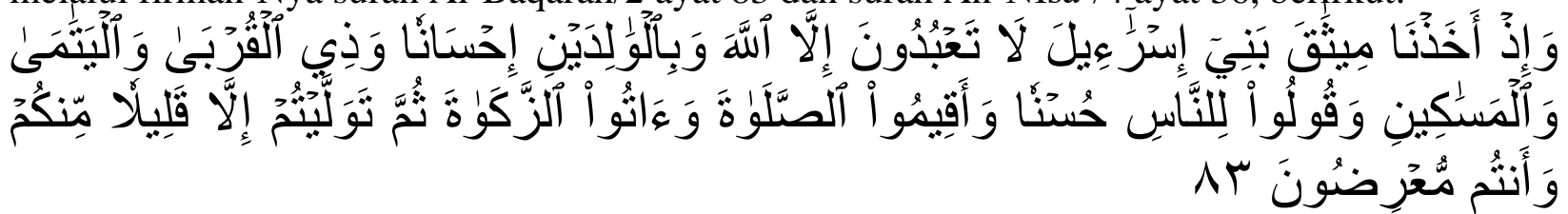

Dan (ingatlah), ketika Kami mengambil janji dari Bani Israil (yaitu): Janganlah kamu menyembah selain Allah, dan berbuat kebaikanlah kepada ibu bapa, kaum kerabat, anak-anak yatim, dan orang-orang miskin, serta ucapkanlah kata-kata yang baik kepada manusia, dirikanlah shalat dan tunaikanlah zakat. Kemudian kamu tidak memenuhi janji itu, kecuali sebahagian kecil daripada kamu, dan kamu selalu berpaling. (Q. S. Al-Baqarah/2: 83).

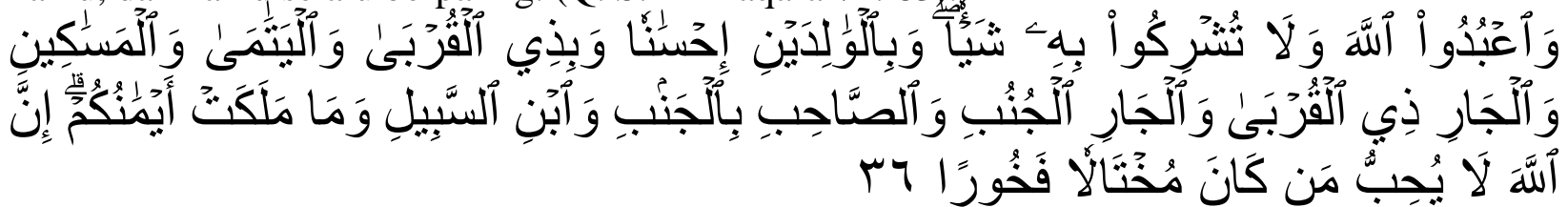

Sembahlah Allah dan janganlah kamu mempersekutukan-Nya dengan sesuatupun. Dan berbuat baiklah kepada dua orang ibu-bapa, karib-kerabat, anak-anak yatim, orang-orang miskin, tetangga yang dekat dan tetangga yang jauh, dan teman sejawat, ibnu sabil dan hamba sahayamu. Sesungguhnya Allah tidak menyukai orang-orang yang sombong dan membangga-banggakan diri. (Q. S. An-NIsa'/4: 36).

Kesimpulan

Bangunlah relasi di atas Zawiyah sebagai landasan kehidupan, agar mampu mencapai kehidupan yang penuh dengan kasih sayang Allah SWT, hidup yang penuh dengan kedamaian, ketentraman, kebahagiaan. Dan kelak di akhirat termasuk yang dikumpulkan bersama golongan orang-orang shaleh. Dengan terbentuknya relasi yang dibangun di atas Zawiyah dengan Allah SWT secara istiqamah, maka akan tercermin mampu membentuk relasi yang baik bersama sesama manusia. Sehingga akan tercipta kehidupan yang penuh dengan kedamaian, kesejahteraan dan penuh keadilan. 


\section{Daftar Pustaka}

\section{Al-Qur'ân Al-Karîm}

Al-Qur'ân Al-Karîm bi ar-Rasm al-Utsmâî, Al-Insân al-'Alaqah al-Akhlaqiyah, Damsyiq: Dâr al-Ma'rufâh, cet. 4, $1420 \mathrm{H}$.

Abd al-Baqi, Muhammad Fuad, Al-Mufahras li Alfaz Al-Qur'ân Al-Karîm, Mesir: Dâr al-Hadits, $1422 \mathrm{H} / 2001 \mathrm{M}$.

Abu, Muhammad Thal'ah Sabri, Ad-Du'ah ila Allah fì Al-Qur'ân Al-Karîm, Mesir: 1986.

Ahmad, Jamil, Seratus Muslim Terkemuka, Jakarta: Pustaka Firdaus, cet. 8, 2003.

Agustian, Ary Ginanjar, ESQ Emotional Spirittual Quotient, Jakarta: Arga, cet. 1, 2001.

Ali, Atabik dan Ahmad Zuhdi Muhdlor, Kamus Kontemporer Arab-Indonesia, Yogyakarta: Yayasan Ali Maksum, cet. 1, 1996.

Ali, Yunasril, Pilar-pilar Tasawuf, Jakaarta: Kalam Mulia, cet. 2, 1999.

Al-Adhîm, Zakki ad-Dîn 'Abd, Mukhtashar Shahîh Muslim, Mesir: Dâr al-Hadits, 2002.

Al-Alusi, Abî al-Fadhl Shihab ad-Dîn Rûh al-Ma'ânî fî Tafsîr Al-Qur'ân Al- 'Azhîm wa as-Sab' al-Matsânî, Mesir: Dâr al-Hadîs, 2005.

Al-Ashfahani, Ar-Raghib, Mu'jam Mufradât Alfazh Al-Qur'ân, Beirut: Dâr al-Fikr, TT.

Al-'Asqalaani, Ibn Hajar, Fath al-Bâarî Fî Shahîh al-Bukhari, Mesir: Maktabah Mishr, 2001. 
Al-'Azîz, Amîr Abd, At-Tafsîr asy-Syâmil li Al-Qur'ân Al-Karîm, Mesir: Dâr as-Salâm, jilid. 1, cet. 1, 2000.

Al-Banna, Gamal, Tafsîr Al-Qur'ân Al-Karîm Baina al-Qudâmâ wa al-Muhadditsîn, edisi terjemah: Evolusi Tafsîr dari Jaman Klasik hingga Jaman Modern, penerjemah: Novriantoni Kahar, Jakarta: Qisthi Press, cet. 1, 2004.

Al-Ishfahani, Abu al-Qasim Abu al-Husain bin Muhammad al-Ragib, Al-Mufradât fî̀ Garîb Al-Qur'ân, Mesir: Mustafâ al-Bâb al-Halâbî, 1961.

Al-Jamal, Muhammad Abd al-Mun'im, At-Tafsîr al-Farîd Lil Qur'â Al-Majîd, Kairo: Research Publicaation Dept, cet. 1, 1952.

Al-Jazairi, Abu Bakar Jabir, Tafsîr Al-Qur'ân Al-Aisir, penerjemah: M Azhari Hatim dan Abdurrahman Mukti, Jakarta: Darus Sunnah, cet. 2, 2011.

Al-Jurzani, Asy-Syarîf bin Muhammad, Kitâb at-Ta'rifât, Beirut: Dâr al-Kutub al-Islâmiyah, cet. $1,2012$.

Al-Khalidy, Shalah, Kisah-kisah Al-Qur'ân Pelajaran dari Orang-orang Dahulu, penerejemah: Setiawan Budi Utomo, Jakarta: Gema Insani Press, cet. 3, 2000.

Al-Maghlouth, Sami bin Abdullah, Atlas Tarikh al-Anbiyâ' wa ar rasul, edisi terjemah: Atlas Sejarah Para Nabi \& Rasul Menggali Nilai-nilai Kehidupan para Utusan Allah, penerjemah: Qasim Shaleh, dkk, Jakarta: Almahera, cet. 4, 2012.

............, Sami bin Abdullah, Atlas Tarikh li Sirah ar_rasul, edisi terjemah: Atlas Perjalanan Hidup Nabi Muhammad Napak Tilas Jejak Perjuangan dan Dakwah Rasulullah, penerjemah: Dewi Kournia Sari, dkk, Jakarta: Almahera, cet. 4, 2011.

Al-Maraghi, Ahmad Mushthafâ, Tafsîr al-Marâghî, Beirut: Dâr al-Fikr, t.th.

Al-Mawardi, Abi al-Hasan Ali bin Muhammad bin Habib al-Bashri, Adab ad-Dunyâ wa ad-Dîn, Beirut: Dâr al-Fikr, tth.

Al-Mun'im, Muhammad Abdul, Al-Jamal at-Tafsîr al-Farîd lî Al-Qur'ân Al-Majîd, Kairo: Research Publication Dept, cet. 1, 1952.

An-Naisâbûrî, Abî Hasan Muslim bin al-Hajâj al-Qusyairî, Shahih Muslim, Mesir: Dâr al-Hadîs, cet. 1, 1997.

Al-Qadhah, Muhammad 'Isham Muflih, Al-Wadhih fì Ahkami at-Tajwid ma' Asalah lilmunaqasah wa Tamrinât, Al-Ardan: Dâr al-Nafais, cet. 4, 2003.

Al-Qadri, Muhammad Tahir, Fatwa tentang Teririsme dan Bom Bunuh Diri, penerjemah: Yudi Wahyudin dan Riswan Kurniawan, Jakarta: Minhaj al-Qur'ân International, cet. 1, 2014.

Al-Qâsimiy, Muhammad Jamâl ad-Dîn, Tafsîr al-Qâasimiy al-Musammâ Mahâsin at-Ta'wîl, Mesir: Dâr al-Hadîs, cet. 1, 2003.

Al-Qaththan, Manna' Khalil, Mabâhis fì 'Ulum Al-Qur'ân, Mekkah: Dâr al- Su'udiyyat, t.th.

Al-Qunawi, Sadr ad-Din, 'Ijaz al-Bayân fì Tafsîr Um Al-Qur'ân, Beirut: Dâr al-Katab al-Ilmiyah, cet. $1,2005$.

Al-Qurthubi, Abî Abdillah Muhammad bin Ahmad al-Anshari, Al-Jâmi' li Ahkam Al-Qur'ân, Beirut: Dâr al-Kutub wa al-Ilmiyah, cet. 1, 1988.

Amali, Planning \& Organisasi Da'wah Rasulullah, Bandung: PT Al-Ma'arif, cet. 1, 1986.

Amstrong, Amatullah, Khazanah Istilah Sufi: Kunci Memasuki Dunia Tasawuf, penerjemah: M S Nashrullah dan Ahmad Baiquni, Malaysia, A S Noordeen, cet. 3, 1998.

An-Nawawi, Muhyi ad-Dîn Yahya bin Syaraf Abî Zakariya, At-Tibyân fî̀ Adab Hamalah Al-Qur'ân, Beirut: Dâr al-Nafaas, cet. I, 1404 H/1984 M.

., Shahih Muslim bi Sharh an-Nawawi, Beirut: Dâr al-Ihya at-Tuath al-'Arabiy, 2000. 
Ar-Razi, Fakh al-Din, At-Tafsîr al-Kabîr, ditahqiq oleh Khalîl Muhyiddîn, Beirut: Dâr al-Fikr, 1994.

Ar-Rifai, Muhammad Nashib, Kemudahan dari Allah Ringkasan Tafsîr Ibnu Katsîr, penerjemah: Syihabuddin, jilid. 1,2,3,4, Jakarta: Gema Insani, cet. 3, 2001.

Ash-Shâlih, Shubhi, Mabâhis fî 'Ulum Al-Qur'ân, Beirut: Dâr al-'Ilm Lilmalayin, 1988.

As-Suyûthî, Jalâl ad-Dîn 'Abd ar-Rahmân bin Abî Bakar, Ad-Durr al-Mantsûr fî̀ at-tafsîr al-Ma'tsûr, Beirut: Dâr al-Kutub al-'Ilmiyah, cet. 2, 2004.

Asy-Sya'râwî, Muhammad Mutawali, Tafsîr asy-Sya'râwî, jilid. 1, 2, 12, 17, Kairo: Idarah al-Kutub wa al-Maktabat, 1411 H/1991 M.

Asy-Syaibany, Omar Mohammad al Toumy, Falsafah at-Tarbiyyah al-Islamiyyah, edisi terjemah: Falsafah Pendidikan Islam, penerjemah: Hasan Langgulung, Jakarta: Bulan Bintang, cet. 1, 1979. Asy-Syaukani, Muhammad bin 'Ăli bin Muhammad, Fath Qadîr al-Jami' baina Fan ar-Riwayah wa ad-Dirayah min 'Ilm at-Tafsîr, Beirut: Dâr al-Fikr, cet. 1, 1983.

Asy-Syanqithi, Adwa'ul Bayâ Tafsir Al-Qur'ân dengan Al-Qur'ân, Penerjemah: Fathirazi, Jakarta: Pustaka Azzam, cet. 1, 2006.

Ath-Thabari, Abû Ja'far Muhammad bin Jarîr, Jâmi' al-Bayân fî Tafsîr Ayi Al-Qur'ân, jilid. 1, 4, 7, 8, 9, Beirut: Dâr al-Fikr , 1988.

Ats-Tsalabah, Sayyid Abdurramân, Al-Jawâhir al-Hisan fî Tafsîr Al-Qur'ân, Beirut: Dâr al-Kutub al-'Ilmiyah, cet. 5, 1996.

Ash-Shabuny, Mohammad Ali, At-Tibyân fî 'Ulum Al-Qur'ân, edisi terjemahan: Pengantar Study Al-Qur'ân (At-Tibyân), penerjemah: Moch Chudlori Umar dan Moh Matsna HS, Bandung: PT Alma'arif, cet. 4, 1996.

Asy-Syaukani, Muhammad bin 'Ăli bin Muhammad, Fath al-Qadîr al-Jâmi' baina Fan ar-Riwayah wa ad-Dirayah min 'Ilm at-Tafsîr, Beirut: Dâr al-Fikr, cet. 1, 1983.

Aziz, M Amin, Pesan Tuhan untuk Membangun Kembali Karakter Bangsa, Jakarta: Dai fiah Qalilah, cet. 1, 2012.

Azra, Azyumardi, Pendidikan Islam Tradisi dan Modernisasi Menuju Milenium Baru, Jakarta: Logos Wacana Ilmu, cet. 4, 2002.

Az-Zuhaili, Wahbah, At-Tafsir al-Munîr, jilid. 1, 2, 5, Beirut: Dâr al-Fikr, cet. II, 1426 H/2005 M. At-Tafsîr al-Wasîth, jilid. 1, 2, 3, Beirut: Dâr al-Fikr al-Mu'hsir, cet. 1, 2001.

Baharuddin, Paradigma Psikologi Islam; Studi tentang Elemen Psikologi dan Al-Qur'ân, Yogyakarta: Pustaka Pelajar, cet. 1, 2004.

Bahgat, Ahmed, Stories of The Prophets of Adaam to Muhammad (Peace be Upun Them) Qishash al-Anbiyâ', translated: Muhammad Mushtafa Gemea'ah Office of The Grand Imam, Sheikh Al-Azhar, Cairo: Islamic Home Publishing \& Distribution, 1997.

Basuki, Sulistyo, Metode Penelitian, Jakarta: Penaku, cet.2, 2010.

Basyîr, Abi al-Hasan Muqâtil bin Sulaimân bin, Tafsîr Muqâtil bin Sulaimân, Beirut: Dâr al-Kutub al-'Ilmiyah, cet. 1, 2003.

Bungin, Burhan (Ed), Metodologi Penelitian Kualitatif Aktualisasi Metodologis ke Arah Varian Kontemporer, Jakarta: PT RajaGrafindo Persada, cet. 8, 2011.

......., Burhan (Ed), Analisis Data Penelitian Kualitatif Pemahaman Filosofis dan Metodologis ke Arah Penguasaan Model Aplikasi, Jakrta: PT RajaGrafindo Persada, cet. 8, 2011.

Bustaman, Risman, Keteladanan Nabi Ibrâhîm Menurut Al-Qur'ân, Jakarta: Sekolah Pascasarjana Universitas Islam Negeri Syarif Hidayatullah, 2008. 
Bogle, John, Character Counts The Creation and Building of The Vanguard Group, New York: The Megraw-Hill, Companies, Inc, cet. 1, 2002.

Coats, Wendell John, A Theory of Republican and Related Essays, London and Toronto: Associated University Presses, Inc, 1994.

Covey, Stephen R, The 7 Habits of Highly Effective People (7 Kebiasaan Manusia yang Sangat Efektif), penerjemah: Lyindon Saputra, Pamulang: Binarupa Aksara Publisher, cet. 1, 2013.

Chalil, Moenawar, Kelengkapan Tarikh Nabi Muhammad saw, Jakarta: Gema Insani Press, cet. 1, 2001.

Dahlan, Abdul Aziz, et al, Ensiklopedi Hukum Islam, Jakarta: PT Ichtiar Baru van Haeve, cet. 1, 1997.

Dahri, Harapandi, Pemikiran Teologi Sufistik Syekh Abduk Qodir Jaelani, Jakarta: Wahyu Press, cet. 1, 2004.

Daradjat, Zakiah, dkk, Metodik Khusus Pengajaran Agama Islam, Jakarta: Bumi Aksara, cet. 3, 2004.

........, Ilmu Jiwa Agama, Jakarta: Bulan Bintang, cet. 17, 2005.

........., Psikoterapi Islami, Jakarta: Bulan Bintang, cet. 1, 2002.

Darmiatun, Suryatri, Implementasi Pendidikan Karakter di Sekolah, Yogyakarta: Gama Media, cet. 1, 2013.

Dirks, Jeradl F, Ibrâhîm Sang Sahabat Tuhan, penerjemah: Satrio Wahono, Jakarta: PT Serambi Ilmu Semesta, cet. 2, 2006.

Departemen Pendidikan Nasional, Kamus Besar Bahasa Indonesia Pusat Bahasa, Jakarta: PT Gramedia Pustaka Utama, cet. 4, 2011.

Devries, Manfred Kets, Reflections on Character and Leadership, England: Jossey-Bass, cet. 1, 2009.

Echols, John M dan Hassan Shadily, An English - Indonesian Dictionary - Kamus Inggris Indonesia, Jakarta: PT Gramedia, cet. 26, 2005.

Faqih, Kamal dan Tim Ulama, Tafsîr Nûrul Qur'ân, penerjemah: R Hikmat Danaatmaja, Jakarta: Penerbit al-Huda, cet. 1, 2003.

Farmawi, Abd al-Hayy al, Metode Tafsir Mawdhuiy Suatu Pengantar. Penerjemah: Jamrah, Surya A, Jakarta: Raja Grafindo Persada, 1996, cet. 2.

Firdaus, Slamet, Konsep Manusia Ideal Dalam Al-Qur'ân (Studi Profil al-Musin dalam Perspektif Tafsîr Ayat-ayat Ihsan), Tangerang: Makmur Abadi Press, cet. 1, 2011.

Fishman, Ethan, William D Perdeson, Nork J Rozell, George Washington; Foundation of Presidentil Leadership and Characater, London: Praeger, cet. 1, 2001.

Feillard, Andree, NU Vis-â-vis Negara, Yogyakarata: LKIS, cet. 1, 1999.

Febriani, Nur Arfiyah, Ekologi Berwawasan Gender Dalam Perspektif Al-Qur'ân, Bandung: PT MIzan Pustaka, cet. 1, 2014.

Gulen, Muhammad Fethullah, Cahaya Abadi Muhammad saw Kebanggaan Umat Manusia, editor: Muh Iqbal Santosa, Jakarta: Republika, cet. 1, 2012.

Gusmian, Islah, Khazanah Tafsîr Indonesia dari Hermeneutika hingga Ideologi, Jakarta: Teraju, cet. I, 2003.

Hadziq, Muhammad Ishomuddin, ed, Kumpulan Kitab Karya Hadlratus Syaikh K. H. Muhammad Hasyim Asy'ari, Jombang: Maktabah at-Turats al-Islami, cet. 1, 2007.

Hamka, Tasauf Moderen, Jakarta: Pustaka Panjimas, 2000.

........, Tafsîr al-Azhar, jilid. 1, 3, 5, 6, 9, 11, 12, 17, 23, Jakarta: Panji Masyarakat, TT. 
Hanafi, Muchlis Muhammad dkk, Tafsîr Al-Qur'ân Tematik, Al-Qur'ân dan Kenegaraan, Jakarta: Lajnah Pentashihan Mushhaf Al-Qur'ân, cet. 1, 2012.

......., Tafsîr Al-Qur'ân Tematik, Kenabian (Nubuwwah) dalam Al-Qur'ân, Jakarta: Lajnah Pentashihan Mushhaf Al-Qur'an, cet. 1, 2012.

......, Al-Qur'ân dan Kenegaraan, Jakarta: Lajnah Pentashihan Mushhaf Al-Qur'an, cet. 1, 2012. Hanbali, Ahmad bin Muhammad bin, Al-Musnad, Mesir: Dâr al-Hadîs, cet. 1, 1995.

Hanley, Ryan Patrick, Adam Smith and the Character of Virtue, Cambridge: University Press, cet. $1,2009$.

Hasjmy, A, Dustur Dakwah Menurut Al-Qur'ân, Jakarta: Bulan Bintang, cet. 2, 1984.

Hawwâ, Sa'îd, Al-Asâs fî At-Tafsîr, Mesir: Dâr As-Salâm, cet. 7, 2003.

Hude, M Darwis, Emosi Penjelajahan Religio-Psikologis tentang Emosi Manusia di dalam Al-Qur'ân, Jakarta: Erlangga, cet. 1, 2006.

......., Logika Al-Qur'ân Pemaknaan Ayat Dalam Berbagai Tema, Jakarta: PT Nagakusuma Media Kreatif, cet. 1, 201.

Husaini, Adian, Pendidikan Islam Membentuk Manusia Berkarakter \& Beradab, Jakarta: Cakrawala Publishing \& Adabi Press, cet. I, 1433 H/2012 M.

Hutcheon, Pat Duffy, Building Character and Culture, London: Praeger, cet. 1, 1999.

Ikbar, Yanuar, Metodologi Penelitian Sosial Kualitatif Panduan Membuat Tugas Akhir/Karya Ilmiah, Bandung: PT Refika Aditama, cet. 1, 2012.

Ikhwan, Muahammad, Investagion of Flow and Pressure Characteristic around Pyramidal Building, Karlsruhe: Universitatsverlag, cet. 1, 2005.

Jalaluddin, Teologi Pendidikan, Jakarta: PT Raja Grafindo Persada, 2003.

Jazuli, Ahzami Samiun, Hijrah Dalam Pandangan Al-Qur'ân, penerjemah: Eko Yulianti, Jakarta: Gema Insani, cet. I, 1427 H/2006 M.

Jones, Ffion Mair, The Bard a Very Singular Character Lolo Morgawg Margilania and Privat Culture, Cordiff: University of Wales Press, cet. 1, 2010.

Klann, Gene, Building Character Strengthening The Heart of Good Leadership, San Francisco: John Wiley \& Sons, Inc, cet. 1, 2007.

Kesuma, Dharma, dkk, Pendidikan Karakter Kajian Teori dan Praktek di Sekolah, Bandung: PT Remaja Rosdakarya, cet. 1, 2011.

Kodir, Abdul, Konsep Manusia Dalam Al-Qur'ân sebagai Dasar Pengembangan Pendidikan, Jakarta: Disertasi UIN Syarif Hidayatullah, 2007.

Kurniawan, Syamsul, Pendidikan Karakter Konsepsi dan Implemnetasinya secara Terpadu di Lingkungan Keluarga, Sekolah, Perguruan Tinggi, dan Masyarakat, Jakarta: Ar-Ruzz Media, cet. $1,2013$.

Lickona, Thomas, Character Matters, New York, Touchstone Rockefeller Center, 2004.

........., Educating for Character, edisi terjemahan: Mendidik untuk Membentuk Karakter, penerjemah: Juma Abdu Wamaungo, Jakarta: PT Bumi Aksara, cet. 1, 2012.

Lee, Philip Yunglie, 250 Essential Chinese Characters, Singapore: Tuttle Publishing, volume 1, cet. 1, 2009.

........ 250 Essential Chinese Characters, volume 2, cet. 1, 2009

Marif, Ahmad Syafii, Studi tentang Percaturan dalam Konstituante Islam dan Masalah Kenegaraan, Jakarta: LP3ES, cet. 2, 1987. 
Majid, Abdul dan Dian Andayani, Pendidikan Karakter Perspektif Islam, Bandung: PT Remaja Rosdakarya, cet. 1, 2011.

Madjid, Nurcholis, Islam Doktrin dan Peradaban, Jakarta: Yayasan Waqaf Paramadina, cet. 4, 2001.

........, Islam Kemodernan dan Keindonesiaan, Bandung: Mizan, cet. 4, 1991.

Makmun, Abin Syasuddin, Psikologi Kependidikan Perangkat Sistem Pengajaran Modul, Bandung: PT Remaja Rosdakarya, cet. 1, 2002.

Mandhur, Ibn, Lisan al- 'Rabiy, jilid. 2, 5, 6, 7, 9, Mesir: Dâr al-Hadits, 2003.

Megawangi, Ratna, Pendidikan Karakter Solusi yang Tepat untuk Membangun Bangsa, Bogor: Indonesia Heritage Foundation, cet. 1, 2004.

Mubarok, Achmad, Solusi Krisis Keruhanian Jiwa Manusia Moderen Dalam Al-Qur'ân, Jakarta: Paramadina, cet. 1, 2000.

Mufid, Sofyan Anwar, Islam \& Ekologi Manusia, Bandung: Nuansa, cet. 1, 2010.

........, Ekologi Manusia dalam Perspektif Sektor Kehidupan dan Ajaran Islam, Bandung: PT Remaja Rosdakarya, cet. 1, 2010.

Muhajir, Noeng, Metodologi Penelitian Kualitatif, Yogyakarta: Rake Arasin, 1996.

Mulyasa, H E, Manajemen Pendidikan Karakter, Jakarta: PT Bumi Aksara, cet. 2, 2012.

Muslim, Mushthafâ, Mabâhits fì al-Tafsîr al-Maudlu'i, Beirut: Dâr al-Qalam, cet. I, 1998.

Mustaqim, Abdul, Madzahibut Tafsîr Peta Metodologi Penafsiran Al-Qur'ân Periode Klasik hingga Kontemporer, Yogyakarta: Nun Pustaka, cet. 1, 2003.

Moleong, Lexi J, Metodologi Penelitian Kualitatif, Bandung: PT Remaja Rosdakarya, cet. 31, 2013.

Naim, Ngainum, Charakter Building Optimalisasi Peran Pendidikan dalam Pengembangan Ilmu \& Pembentukan Karakter Bangsa, Jogjakarta: Ar-Ruzz Media, cet. I, 2012.

Nashir, 'Athiyah Qabil, Ghayâh al-Murîd fì 'Ilm al-Tajwîd, Riyadh: ad-Dakwah wa al-Irsyâd, $1408 \mathrm{H}$, cet. 3.

Nashir, Muahammad Makki, , Nihâyah al-Qaul al-Mufíd fî 'Ilm al-Tajwîd, Bogor: Maktabah 'Arafah, TT.

Nata, Abuddin, Akhlak Tasawuf dan Karakter Mulia, Jakarta: PT Raja Grafindo Persada, cet. 13, 2014.

Nazir, Moh, Metode Penelitian, Jakarta: Ghalia Indonesia, 1988.

Novick, Bernard, Jeffrey S Kress, Maurice J Elias, Building Learning Communities With Character, How to Integrate Academic Social and Emotional Learning, USA: Association for Supervision and Curriculum Development (ASCD), cet. 1, 2002.

Patching, Keith, Leadeship, Character and Strategy Exploring Divessity, London: Palgrave Macmillan, cet. 1, 2007.

Pritchard, Ray, The ABC'S of Wisdom Building Character with Solomon, Chicago: Moody Press, cet. 1, 1997.

Qardhawi, Yusuf, Kaifa Nata' amalu Ma'Al-Qur'ân Al- 'Azhîm, edisi terjemahan: Berinteraksi dengan Al-Qur'ân, penerjemah: Abdul Hayyie al-Kattani, Jakarta: Gema Insani, cet. I, $1420 \mathrm{H}$ /1999 M.

Quthb, Sayyid, Fî Zhilal Al-Qur'ân, Beirut: Dâr asy-Syuruq, 2008.

Qodir, Abdul, Konsep Manusia Dalam Al-Qur'ân sebagai Dasar Pengembangan Pendidikan, Jakarta: Disertasi UIN Syarif Hidayatullah, 2007.

Rahmat, Jalaluddin, Islam Alternatif, Bandung: Mizan, 1991. 
Rajab, Muhammad, Da'wah al-Rusul ila Allah, Mesir: Yayasan Sa'id al-Mathba'ah, cet. 1, 1986. Ratna, Nyoman Kutha, Metodologi Penelitian Kajian Budaya dan Ilmu Sosial Humaniora pada Umumnya, Yogyakarta: Pustaka Pelajar, cet. 1, 2010.

Rich, Dorothy, Building Our Children's Character and Acievement for School and Life, Canada: MegaSkills, cet. 5, 2008.

Ridha, Muhammad Rasyid, Tafsîr Al-Qur'ân Al-Hakîm (al-Manar), ditahqiq oleh Ibrahim Syamsuddin, Beirut: Dâr al-Fikr, 1999.

Rifai, Achmad, Narkoba Di Balik Tembok Penjara, Yogyakarta: Aswaja Pressindo, cet. 1, 2014. Rees, James C, George Washington's Leadership Lessons; What The Father of Our Country Can Teach us a Bout Effective Leadership and Character, Canada: John Wiley \& Sons, Inc, cet. 1, 2007.

Sagolla, Dom, 140 Character A Style Guide for The Short Form, Canada: John Wiley \& Sons, Inc, cet. 1, 2009.

Sahlan, Asmaun dan Angga Teguh Prastyo, Desain Pembelajaran Berbasis Pendidikan Karakter, Jogjakarta: Ar-Ruzz Media, cet. 1, 2012.

Said, Hasani Ahmad, Diskursus Munasabah Al-Qur'ân Kajian atas Tafsîr Al-Mishbâh, Tanggerang Selatan: Puspita Press, cet. 1, 2011.

Salahuddin, Anas dan Irwanto Alkrienciehie, Pendidikan Karakter: Pendidikan Berbasis Agama dan Budaya Bangsa, Bandung: Pustaka Setia, cet. 1, 2013.

Salim, Muhsin, Ilmu Qira 'at Sepuluh, Jakarta: Majelis Kajian Ilimu-Ilmu Al-Qur'ân, cet. 1, 2007. Samani, Muchlis dan Hariyanto, M.S, Konsep dan Model Pendidikan Karakter, Bandung: PT Remaja Rosdakarya, cet. 1. 2011.

Santana, Septiawan K, Menulis Ilmiah Metodologi Penelitian Kualitatif, Jakarta: Yayasan Pustaka Obor Indonesia, cet. 2, 2010.

Santoso, Slamet, Teori-Teori Psikologi Sosial, Bandung: PT Refika Aditama, cet. 1, 2010.

Saleh, Akh Muwafik, Membangun Karakter dengan Hati Nurani Pendidikan Karakter untuk Generasi Bangsa, Jakarta: Erlangga, cet. 3, 2012.

Sarwono, Sarlito W, Psikologi Dalam Praktek, Jakarta: Restu Agung, edisi revisi, 2005.

Sarwono, Sarlito W dan Eko A Meinarno, Psikologi Sosial, Jakarta: Salemba Humanika, cet. 1, 2011.

Singarimbun, Masri dan Sofian Efendi (ed), Metode Penelitian Survei, Jakarta: LP3S, 1989.

Schmidt, Victoria Lynn, 45 Character Methic Models for Creating Original Characters, USA: Writer's Digest Books, cet. 1, 2007.

Sjarkawi, Pembentukan Kepribadian Aneka Peran Moral, Intelektual, Emosional, dan Sosial sebagai Wujud Integritas Membangun Jati Diri, Jakarta: PT Bumi Aksara, 2006.

Suherman, Eman, Kiat Sukses Membangun SDM Indonesia Melalui Pendidikan dan Pelatihan Entreprenuership, Bandung: Afabeta, cet. 1, 2012.

Surasman, Otong, Metode Insani Kunci Praktis Membaca Al-Qur'ân Baik dan Benar: Jakarta: Gema Insani Press, cet. 3, 2004.

Suryabrata, Sumadi, Psikologi Kepribadian, Jakarta: PT Rajagrafindo Persada, edisi. 1, 2008.

Sutrisno, dan Muhyidin Albarobis, Pendidikan Islam Berbasis Problem Sosial, Jogjakarta: Ar-Ruzz Media, cet. 1, 2012. 
Shahrur, Muhammad, Al-Kitâb wa Al-Qur'ân : Qira'ah Mu'ashirah, edisi terjemahan: Prinsip dan Dasar Hermeneutika Al-Qur'an Kontemporer, penerjemah: Sahiron Syamsuddin dan Burhanuddin Dzikri, Yogyakarta: eLSAQ Press, cet. 1, 2004.

Shihab, Muhammad Quraish, Tafsîr al-Mishbâh, jilid. 1, 2, 3, 4, 5, 6, 7, 8, 10, 11, 12, 13, 14, 15, Jakarta: Lentera Hati, cet. I, 2000.

.......... Tafsir Al-Qur'ân Al-Karîm Tafsîr atas Surat-surat Pendek Berdasarkan Urutan Turunnya Wahyu, Bandung: Pustaka Hidayah, cet. II, 1997.

........., Membumikan Al-Qur'ân, Bandung: PT Mizan Pustaka, cet. xxvi, 2003.

........., Menyingkap Tabir lahi Asma al-Husna dalam Perspektif Al-Qur'ân, Jakarta: Lentera Hati, cet. 5, 2003.

........., Mukjizat Al-Qur'ân Ditinjau dari Aspek Kebahasaan Isyarat Ilmiah dan Pemberitaan Gaib, Bandung: Mizan, cet. 4, 1998.

........, Wawasan Al-Qur'ân, Bandung: PT Mizan Pustaka, cet. xiv, 2003.

........., Muhammad Quraish dkk, Sejarah \& 'Ulum Al-Qur'ân, Jakarta: Pustaka Firdaus, cet. 3, 2001.

Stanislavski, Constantin, Building Character, London: A Methuen Paper Bark, cet. 18, 2001.

Syubar, As-Sayyid Abdullah, Tafsîr Al-Qur'ân Al-Karîm, Beirut: Al-'Alami Librari, cet. 1, 1950.

Syurbasyi, Ahmad, Study Tentang Sejarah Perkembangan Tafsîr Al-Qur'ân Al-Karîm, Jakarta: Kalam Mulia, cet. I, 1999.

Taimiyah, Taqiyy ad-Dîn ibn, At-Tafsîr al-Kabîr, Beirut: Dâr al-Kutub al-'Ilmiyah, TT.

Tasmara, Toto, Kecerdasan Ruhaniyah (Transcendental Intellegece) Membentuk Kepribadian yang Bertanggung Jawab, Profesional, dan Berakhlak, Jakarta: Gema Insani Press, cet. 2, 2006.

Thahun, Ahmad Muhammad, Ad-Du'ah ila Allah Darasah wa Tathbiq, Mesir: Maktabah at-Turats al-Islamiyah, cet. 5, 1995.

Thalbah, Hisam, et al, Kemukjizatan Alam Semesta Ensiklopedia Mukjizat Al-Qur'ân dan Hadis, penerjemah: Syarif Hade Masyah, et al, Jakarta: PT Sapta Sentosa, cet. 4, 2010.

Umairah, Abdurrahman, Rijâl wa Nisấ' Anzal Allah fihim Qur'ân, edisi terjemah: Tokoh-tokoh yang Diabadikan Al-Qur'an, Jakarta: Gema Insani Press, cet. I, 2000.

Walgito, Bimo, Pengantar Psikologi Umum, Yogyakarta: Andi Offset, cet. 4, 1986.

Wibowo, Susatyo Budi, Dahlan Asy'ari, Jojakarta: Diva Press, cet. 1, 2011.

Yaqub, Ali Mustofa, Sejarah dan Metode Dakwak Nabi, Jakarta: PT Pustaka Firdaus, cet. 1, 1997.

Yusuf, Syamsu, dan Juntika Nurihsan, Teori Kepribadian, Bandung: PT Remaja Rosdakarya, cet. 2, 2008.

Zakariya, Abû al-Husain Ahmad bin Faris bin, Mu'jam al-Maqâyis fì al-Lughah, Beirut: Dâe al-Fikr, cet. 1, 1994.

Zaleznik, Abraham, Hegdehogs and Foxes, Character, Leadership, and Command in Organizations, New York: Palgrave Macmillan, cet. 1, 2008.

Zubaedi, Desain Pendidikan Karakter Konsepsi dan Aplikasinya dalam Lembaga Pendidikan, Jakarta: Kencana, , cet. 1, 2012. 